\title{
LA INTENSIFICACIÓN SENSORIAL EN DETRIMENTO DE LA NARRATIVA EN EL ESPECTADOR CINEMATOGRÁFICO CONTEMPORÁNEO. LOS CAMBIOS A PARTIR DE LA EXPERIENCIA SENSIBLE DEL ESPECTADOR
}

\section{SENSORY ENHANCEMENT IN DETRIMENT OF THE NARRATIVE IN THE CONTEMPORARY CINEMATOGRAPHIC SPECTATOR. CHANGES BASED ON THE SPECTATOR'S SENSORY EXPERIENCE}

FECHA DE RECIBO: JUNIO 4, 2012

FECHA DE ACEPTACIÓN: JUNIO 29, 2012

\section{MARK MICHAEL BETTS ALVEAR}

Diseñador gráfico egresado como tecnólogo de la Universidad Autónoma del Caribe en Barranquilla, Profesionalizado en la Universidad Jorge Tadeo Lozano de Cartagena. Candidato a Maestría en Diseño Comunicacional en la Universidad de Buenos Aires, Argentina. Docente catedrático del Programa de Diseño Gráfico en la Universidad Autónoma del Caribe.

\section{RESUMEN:}

Los regímenes escópicos o modos de percibir epocales, se han visto condicionados a través de la historia evolutiva del hombre, a través de las hegemonías estilísticas y los medios técnicos producto de los avances tecnológicos. El espectador surge como una figura convertida en su objetivo, gracias a los creadores de dispositivos que apelaban a la intensificación sensorial y a su narrativa. El teatro, la fotografía, el cine, la televisión y las plataformas interactivas, aparecen como sus canales de distribución por excelencia, reestructurando las formas de sentir y de pensar a partir de sus modos artificiales de emisión. La dinámica entre sensación y narrativa aparecen como estímulos que envuelven al espectador en una experiencia cada vez mas intensa, gracias a las intenciones sinestésicas y cinestésicas que se reactualizan detrás de ellos.

\section{PALABRAS CLAVE:}

Cine, sensorial, espectador, narrativa, sinestesia, cinestesia, percepción

\section{ABSTRACT:}

Scopic regimes or ways of perceiving by timeframes have been conditioned by the evolutionary history of man, through the stylistic hegemonies and technical means product of technological advances. The spectator emerges as a figure converted in his own objective, thanks to the creators of devices appealing to sensory intensification and its narrative. Theater, photography, film, television and interactive platforms, appear as excellent distribution channels, restructuring the ways of feeling and thinking given their artificial modes of emission. The dynamic between feeling and narrative appear as stimuli to envelop the viewer in an increasingly intense experience, thanks to the intentions that synaesthetic and kinesthetic reactualize behind them

\section{KEYWORDS:}

Film, sensory, viewer, narrative, synaesthesia, kinesthesia, perception 


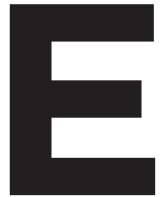

l concepto estética que deviene del griego aisthetikê y aisthesis que apuntan a la percepción y a la sensibilidad, evidencian a razón de algunos pensadores griegos entre ellos Sócrates y Platón, la presencia de un mundo sensible con el que se tiene contacto a través de los sentidos, y otro inteligible que procesa esas percepciones que ingresan al cuerpo a partir de la razón, en el ademán de la generación de conocimiento.

Alexander Baumgarten en 1750 expone el término estética bajo la expresión "cognitio sensitiva o conocimiento sensible" (STRAUVEN Wanda 2006: p.321), como la facultad de percepción de una forma de conocimiento ambiguo y confuso, de todo aquello con lo que se tiene contacto y que entra al cuerpo a través de procesos sensibles, opuestos a las formas claras del conocimiento conceptual. Una tesis relacionada a la alegoría de Platón, conservando las proporciones de lo que SEEL Martin (2010), denomina "animación de los aspectos"(p.39) y que hace alusión a la manera en que un objeto aún siendo inmóvil se detiene en un punto de aparecer.

Las obras de Francis Bacon sirven como ejemplo a las teorías de Baumgarten y de Seel a la manera en que una forma parece cobrar vida de manera ambigua en una mezcla de arte figurativo y abstracción. Las pinturas de Bacon parecen a la manera de sus deformaciones, dar la ilusión de aparecer y desaparecer en una transformación que empuja al espectador a una sensación confusa de movimiento, que fluye en un ir y venir interno entre lo móvil y lo inmóvil generando procesos sinestésicos, frutos de la contemplación. Cuando se tiene contacto con este fenómeno el acto de aparecer se acentúa más en la experiencia sensitiva de la forma como acto de presentación, subordinando el discurso representativo que involucra el conocimiento conceptual, lo que Gilles Deleuze catalogaría como devenires sensoriales, atrapados en una cuestión de expresión.

Antes del advenimiento del cine, los avances tecnológicos de la imagen estática fotográfica lograda con materiales sensibles a la luz por Niépce y perfeccionada por Daguerre, trajo como consecuencia una ruptura de la forma de ver la mímesis, tal como lo venía materializando la pintura desde siglos anteriores, hacia una copia mucho más fiel de lo que podía ofrecer la mejor pintura. Aunque la fotografía se usó como fines sociales, tuvo un gran protagonismo como mecanismo científico debido a que llevó al hombre a ver lo que antes el ojo de manera natural no podía detectar.

En 1895, cuando los hermanos Lumiére en Francia le mostraran al mundo la ilusión de la imagen en movimiento, la manera en que se concibiera la cultura visual de la época traería consigo un rompimiento en la forma de percibir las cosas, mucho más impactante que cuando surgió la fotografía. Aunque el objetivo de los hermanos Lumiére era mostrar la capacidad de un nuevo medio tecnológico producto de sus investigaciones, el cine en su neonata etapa logra alejar a sus espectadores, de su capacidad de razonamiento gracias a la estética del asombro. El paso de la imagen estática a la ilusión del movimiento lograda con su proyector cinematográfico, obnubiló a todos los que presenciaran el 28 de marzo de 1895 lo que fuese el registro sin saberlo de su primer documental, la salida de los obreros de la fábrica Lumiére en Lyon Monplaisir. En palabras de Gorki Maxim: "de repente un destello extraño pasó a través de la pantalla y la imagen se movió como si cobrara vida [...] la transformación de la imagen fija a la ilusión del movimiento dejó al público sorprendido"(STRAUVEN 2006: p.322).

El público cayó en un estado de estupor al presenciar una ilusión, que emulaba el movimiento que se recreaba cotidianamente bajo sus realidades. Para 1902 Edison pasa públicamente en un teatro con su kinetoscopio, una obra titulada Uncle Josh, que bajo las situaciones proyectadas de la vida cotidiana, un espectador confunde de forma paródica la realidad con lo proyectado. Bajo esta estética del asombro y de la sorpresa, el público se presentaba absorto ante esta nueva lógica de las sensaciones, producto del paso de lo estático al desplazamiento.

Así como la fotografía logró recrear la mímesis mucho más cercana a la realidad en competencia a la que lograse el arte, en un orden no muy diferente, el cine rompió a través de la cognitio sensitiva de la que hablara un siglo antes Baumgarten, el modo de recrear la realidad estética de una nueva época, convirtiéndose en una forma sinestésica que desplazaba el contenido narrativo y todos los regímenes previos a esta nueva forma de composición. Fue en síntesis una ruptura a un orden de a lo que se estaba acostumbrado y les era conocido a las personas de finales del siglo XIX, transportándolos casi que narcótica y voluntariamente hacia un viaje por lo desconocido. "El público se sitúa en los modos conflictivos del aparecer que se transportan de la fotografía a la cinematografía" (STRAUVEN 2006: p.322), en este intersticio entre la calma estática y el movimiento surge el llamado espacio emocional de Eivind Rossaak.

El cine era la máquina que cerraría la era de las máquinas de la última etapa de la modernidad, como una combinación entre fotografía y relojes mecánicos. Con el tiempo pasaría a convertirse en una forma nueva de espectáculo público en los que acostumbrados los espectadores a la ilusión del movimiento, se le inocularon instancias narrativas y semánticas, que con la aparición del audio mejoraron sustancialmente mucho más. Éste, pasó a convertirse en lo que Jean Louis Comolli designara con el término cine monstruo, que se define como una criatura con cabeza de Meliés y cuerpo de Lumiére. Una criatura en el sentido frankestiano derivada hacia un nuevo espectador oscilante que se debate en un estado mixto entre sueño y vigilia. En 
síntesis, el cine llegó a transformarse, en la combinación de un dispositivo tecnológico del siglo XIX y en un mundo del espectáculo para los siglos venideros.

Parece ser según la posición de Deleuze que la pintura, la fotografía y el cine en su etapa de nacimiento, se convirtieron en motores de la estética del asombro, la sorpresa y lo desconocido que bajo la ilusión de lo inexistente como formas de presentación, terminaron al final por convertirse en medios de representación, debido a la combinación de los devenires sensoriales con la semantización y la capacidad discursiva y narrativa que se apropió más tarde de ellos.

El cine como coincidió con la ruptura del ojo y la historia del arte, permitió una relectura como balcón y punto de vista crítico y epistemológico de otros tipos de artes, por eso no es una síntesis de otras artes. Así como acto de estimulación de los sentidos y también como acto representativo, pasa a ser definido como el séptimo arte, tomando en cuenta la existencia de las seis artes previas a el. Con la posterior semantización del cine y la transformación de los nuevos medios de la cultura visual digital del siglo XX y XXI, surge una migración de los medios tradicionales de los espacios públicos a los espacios privados del espectador. En palabras de Dominique Païni (2010): "no hay arte sin reproducción, la reproductibilidad técnica del cine fue el VHS y el Betamax". El cine pasa a contemplarse no solamente desde la silla pública de las salas de proyecciones de estreno, sino también desde el living o "la habitación del espectador en casa" (DARLEY, Andrew, 2010). La majestuosidad de la pantalla gigante, el sonido envolvente Dolby y la climatización del ambiente, pasó a ser compensada por el control total de la función en el hogar. El congelar la imagen al detener la película, el rewind, la cámara lenta, y muchas opciones incluidas en los nuevos reproductores de video hogareños, (al igual que el home theater que emula el sonido circundante de las grandes salas), permitieron compensar con el control, aquellos elementos cualitativos, pertenecientes exclusivamente a los espectáculos públicos cinematográficos. La era de controlar a voluntad los medios que reproducían video en el hogar había llegado.

La aparición de los video juegos, los computadores personales (que podían reproducir y editar video y audio), las películas desarrolladas en entornos artificiales en tercera dimensión y los paseos virtuales, le dieron paso a nuevos fundamentos que traerían consigo una estimulación sensorial que volvería a reescribir la experiencia del espectador, en el que la narrativa y la capacidad discursiva volverían de nuevo a convertirse en el contenido subordinado, de las nuevas estrategias de la figura sensación que ensimismaban al espectador de Deleuze. La versión de "Volver al Futuro" de Steven Spielberg que se proyecta como espectáculo en Orlando, mucho más que un film tiene la apariencia de un paseo virtual. El espectador bajo las sensaciones de sacudidas y estímulos ambientales que desde sus sillas frente a una pantalla percibe, actúan en conjunción con los sucesos de la película, logrando que la concentración se apegue más a emociones mucho más parecidas a un paseo extremo, que el disfrute que hace parte del análisis de una historia que se cuenta en la misma. "El negocio de estas atracciones giran más en torno al espectáculo y la emoción visceral. Como en el caso de los juegos de ordenador, la narración queda subordinada a un tipo de placeres mucho más instantáneos. De forma similar, también implican una intensificación del efecto 'cinestésico*' [...] sin embargo los espectadores/pasajeros no viajan físicamente, se encuentran sentados en una sala" (DARLEY, 2002: p.252-253).

La simulación fue uno de los elementos que la tecnología (de los años 80's y 90's del siglo XX) brindó como herramienta a los productores cinematográficos, en pro de una estimulación sensorial mucho más invasiva orientada al espectador. Este concepto de simulación fue entendido como: "la copia o el legado figurativo de la realidad fenoménica, tanto en una pantalla bidimensional como en términos de espacio virtual tridimensional, que apuntó esta última al realismo figurativo" (DARLEY, 2002) Las películas del cine digital modeladas y animadas en 3D como Toy Story, Finding Nemo, Ratatouille, y aquellas intervenidas por estos avances como El Rey León, The Mask y Jurassic Park, serían las pruebas y resultados de Hollywood a la implementación de las nuevas tecnologías con el cine tradicional, para probar un redimensionamiento del realismo figurativo (este patrón ya estaba dictado por la fotografía y el cine clásico pero bajo la representación de la realidad), que desde los ordenadores prometía la recreación de mundos similares al nuestro, pero administrados bajo nuevas leyes que no podían ser recreadas bajo el mundo natural.

La simulación pasó a convertirse en una de las herramientas más poderosas del cine, en pro de la estimulación de los sentidos, debido a que lograba de manera más eficiente lo que en rodajes convencionales era imposible de realizar. Así los modelados, las interpolaciones y la animación digital, pasaron a convertirse en elementos fundamentales de las nuevas producciones, en una estrategia que intervino y colocaba el acento en las emociones producidas por la estimulación de los efectos especiales, en detrimento y subordinación de la narrativa. El cine muchos años después de consolidarse como medio de representación y de espectáculo para las masas, rompió entonces con las reglas en las que fueran para el siglo XX sus características y atavíos convencionales, como la excitación del alma, los sentidos visuales y auditivos más la discursividad narrativa y semántica que la acompañaba. El lanzamiento de la película "The Matrix" de los hermanos Wachowski en 1999, introdujo lo que Tom Gunning catalogó como "cinema of attractions" (STRAUVEN: p.61). Estos neoproductores 
preocupados más por la estética de la sorpresa y la lógica de las sensaciones, apelaron a un antecedente que les traería no solo fama y reconocimiento internacional, sino que establecerían un nuevo orden de la manera de percibir las composiciones cinematográficas. Gunnin le llamó al fenómeno que lograran los hermanos Wachowsky como: "un concepto de atracción sensible que liberaría el análisis de la película de su hegemonía narrativa, que es dominado por el género, su enfoque y el carácter estructural de una historia"(Idem). La historia del cine parecía reescribirse, era el paralelo en la historia del hombre como el antes y después del mesías, lo que fuera al cine el antes y después de la película Matrix.

El antecedente que tomaran y perfeccionaran fue el artefacto de seis cámaras fotográficas análogas dispuestas en círculo que inventara Eadweard Muybridge, para los años 1880. El experimento consistía en hacer saltar a un hombre mientras se obturaban las seis cámaras fotográficas al mismo tiempo logrando una toma desde ángulos diferentes a la vez. Los hermanos Wachowsky instalaron 122 cámaras fotográficas digitales de alta velocidad en forma de arco, igual como lo hiciera Muybridge.

En la escena donde Trinity se suspende en el aire luego de poco tiempo de comenzada la película, la toma múltiple simula una congelación suspendida en un lapso suave de tiempo y movimiento, al mismo tiempo las cámaras parecieran hacer una toma en paneo circular que en realidad no sucede. "Un gran número de cámaras fotográficas y una serie de imágenes interpoladas están conectadas en una secuencia que simula un movimiento de cámaras imposibles [...] es como si se entrase en un limbo entre los movimientos de la película y la contemplación de otro mundo, una contemplación escultórica" (STRAUVEN: p.325). La realidad del tiempo y el espacio se rompen gracias al bullet time effect (contemplando sorprendidos los espectadores), debido a que era imposible la producción de este nuevo orden estético con cámaras tradicionales.

El cine siendo la objetividad en el tiempo en su tarea de reproducirlo de forma lineal, cruza la frontera de registrar lo que se encuentra fuera del mismo con el bullet time effect. La simulación producto del morph entre cada lente del círculo y la siguiente cámara se hacía necesaria para el suavizado de las transiciones. Deleuze analiza la lógica de las sensaciones como un enfrentamiento entre modos de movilidad e inmovilidad, ese intersticio entre estos dos elementos es lo que acentúa el espacio emocional. Cuando el cambio en los modos de percibir pasa del arte y la fotografía que luchan por congelar lo móvil, a la cinematografía que busca la tarea de reproducir mecánicamente regrabaciones del movimiento, en el punto medio de estas dos facetas el espacio emocional de Rossaak se pasó a lista y se hizo presente.

Deleuze se relaciona con este principio o este intersticio de la siguiente manera. Plantea que la figura es sensación y la lógica de esta sensación pone en conflicto a los medios y el movimiento, como una progresión simulada de algo que verdaderamente se encuentra inmóvil. Toma a la pintura de Bacon y evidencia que ésta crea este conflicto por que produce la sensación de moverse aún estando estática, muy parecido al efecto escultórico que recrearan los productores de Matrix. El fenómeno del bullet time effect trae a colación este efecto escultórico, por que mientras el movimiento y el espacio tiempo son violados, la figura sensación coloca al espectador en una situación inmersiva e inconsciente debido a que el cerebro trata de procesar y de entender un estímulo que es racionalmente imposible. La figura congelada en un instante de tiempo hace alegoría a la escultura que se mantiene estática, pero que como fotograma individual se convierte en una presentación de una realidad y un instante de tiempo congelados.

La violación o el rompimiento del espacio tiempo que generó Matrix y su equipo de efectos visuales dirigido por John Gaeta, logró establecer un vínculo con la carne directa del espectador sumergiéndolo en emociones producto de lo imposible y a una estética de la sorpresa, que técnicamente según tomas convencionales no podría lograrse, generando estímulos no solo sinestésicos sino también cinestésicos a los que se refiere Darley, gracias a la simulación.

La trama de la película trae a colación la alegoría de la caverna de Platón desde ambos aspectos. El mundo virtual y el mundo real bajo el cual Morpheus despierta a los que son aptos para encontrar al elegido, se debate entre el mundo sensible y el mundo inteligible que propusiera Sócrates como maestro mismo de Platón. Precisamente en el minuto 08 con 35 segundos de la película, el protagonista principal 'Neo' abre un libro falso de donde saca un disco. La portada del libro reza Simulacra and Simulation, el mismo título del libro de Baudrillard Simulacro y Simulación. El monólogo de Morpheus frente a Neo: "It is the world that has been pulled over your eyes, to blind you from the truth, that you are a slave. Like everyone else, you were born into bondage, born into a prison that you cannot smell or taste or touch. A prison for your mind"(Matrix. 1999), pone en evidencia la alegoría de la caverna de Platón.

Entonces la figura sensación de Deleuze y la cognitio sensitiva de Baumgarten se encuentran en el plano del mismo mundo sensible al que se refiere Platón, donde el mundo inteligible relegado no hace parte, de una fantasía en la que todo está permitido, por eso estas hazañas imposibles solo tenían lugar en la Matrix y no en el mundo real. Aquello que parecía real bajo la irrealidad era totalmente acertado con la ilusión del rompimiento espacio tiempo, del cual sufrían las personas que estaban siendo cultivadas en estado catatónico. El mismo estado en que se suspende a través de 
la figura sensación al espectador con el bullet time effect.

El efecto escultórico que se revive para los Wachowksy no se acentúa en la inmovilidad, sino en la ilusión de una movilidad suspendida, que captura al espectador y lo sumerge en un hálito de sensaciones cinestésicas con la ambición de aislarlo por determinados lapsos de tiempo de la tradicional narrativa del cine, que al subordinarla le daría espacio al espectador sensual del Deleuze.

Después de cien años, el cine aunque rompiera nuevamente con los modos de excitación de los sentidos en búsqueda de la intensificación sensorial, la sinestesia y la cinestesia producto de ella obliga nuevamente al espectador cinematográfico ahora contemporáneo, a romper con los estigmas de su estética de la percepción. Aunque el discurso narrativo y la significación queden relegados a un segundo plano, no dejan estas de ser importantes, debido a que dentro de la misma sinestesia se obliga al espectador a detectar también los signos ocultos en las películas, que terminan desde su background por complementar esta fenómeno de la percepción en la que un sentido, asume no solo su rol sino el de otro de manera adicional, definiéndolo bajo la frase de: 'cuando el ojo toca'. Un referente es contemplar a través del ojo, la Gioconda de Leonardo. Pero, en el momento en que se comienza a recorrer sus superficies irregulares, debido a la técnica del esfumato y por la prohibición de tocar la obra, es cuando el ojo toca.

\section{REFERENCIAS BIBLIOGRÁFICAS}

STRAUVEN, Wanda. The Cinema of Attractions Reloaded. Amsterdam University Press. Amsterdam 2006.

DARLEY, Andrew. Cultura Visual Digital. Editorial Paidós. Barcelona 2002.

SEEL, Martin. Aesthetics of Appearing. Stanford: Stanford UP. 2005.

DELEUZE, Gills. GUATTARI, Felix. What is Phillosophy?

London. 1994.

DELEUZE, Gills. Francis Bacon: Figures of Sensation.

London. 2003.

COMOLLI, Jean Louis. Ver y Poder, la Inocencia Perdida.

Editorial Nueva Librería. 2007.

PAÏNI, Dominiche. Conferencia Ciclo Cine y Arte Contemporáneo. Godar en el Museo. Elementos inéditos de las exposiciones de Jean Luc Godar en el Centro Pompidou. Espacio Fundación Telefónica. Buenos Aires, Argentina. 2010.

NOTA DE AUTOR: Existe una diferencia entre los conceptos cinestesia y sinestesia. Cinestesia se relaciona con la sensación y la percepción del movimiento, son las sensaciones nacidas de la lógica sensorial, que se transmiten continuamente desde todos los puntos del cuerpo al centro nervioso de las aferencias sensorias. Abarca la sensibilidad visceral o interoceptiva y la propioceptiva cuyo asiento periférico está situado en las articulaciones y los músculos y cuya función consiste en regular el equilibrio y las sinergias. En cuanto que la sinestesia apela a un cruce o a una yuxtaposición de otro orden de los sentidos. Un 